\title{
A ANÁLISE INTERDISCIPLINAR DE PROCESSOS DE LICENCIAMENTO AMBIENTAL NO ESTADO DE MINAS GERAIS: CONFLITOS ENTRE VELHOS E NOVOS PARADIGMAS
}

\section{The interdisciplinary analysis in the Environmental Licensing Proceedings in Minas Gerais State: conflicts between old and new paradigms}

Gelze Serrat Souza Campos Rodrigues Professora Dra. do Instituto de Geografia da Universidade Federal de Uberlândia Uberlândia/MG - Brasil gelcampos@ig.ufu.br

Artigo recebido para publicação em 15/03/2010 e aceito para publicação em 01/07/2010

RESUMO: $\quad$ A interdisciplinaridade tem sido tema constante nas discussões sobre o conhecimento humano, sobre as suas possibilidades frente ao que Morin (2002) denomina de "desafio do século XXI”, ou seja, frente à necessidade de compreensão e enfrentamento dos problemas multidimensionais atuais, tais como os derivados da interação de processos naturais, sociais, econômicos e tecnológicos. Baseado nessa perspectiva, a Secretaria de Meio Ambiente e Desenvolvimento Sustentável do Estado de Minas Gerais, desde 2003, tem promovido o emprego do enfoque interdisciplinar na análise dos processos de licenciamento ambiental, por meio da realização de uma série de ações e procedimentos que buscam a convergência e a integração dos saberes disciplinares dos analistas ambientais. Nesse sentido esse artigo procura expor o processo de inserção da perspectiva interdisciplinar na análise dos processos de licenciamento ambiental do Estado de Minas Gerais. Dessa forma, tomando como base exemplificativa os Pareceres elaborados para Processos de Licença Prévia de empreendimentos de grande porte do setor sucroalcooleiro, julgados no Conselho de Política Ambiental do Triângulo Mineiro e Alto Paranaíba, MG, procura elucidar a contribuição do modelo interdisciplinar para a formulação de novas estratégias e racionalidades para a avaliação de impactos ambientais, bem como as dificuldades para a sua adoção.

Palavras-chave: Licenciamento Ambiental. Interdisciplinaridade. Planejamento Ambiental.

ABSTRACT: The interdisciplinary has been a constant theme in discussions about human knowledge, and its possibilities according to what Morin (2002) calls the "XXI century challenge", in other words, the necessity of understanding and solving the multidimensional current problems, like the ones caused by interaction between the natural, social, economic and technological processes. Basing on this perspective, the Minas Gerais Environmental and Sustainable Development Secretary, since 2003, has promoted the use of the interdisciplinary approach in analyzing the environmental licensing, through various actions and procedures that look for the convergence and integration of the environmental analysts knowledge of their environmental analysts. In this sense this article presents the procedures of insertion of interdisciplinarity in analysis of environmental licensing proceedings from Minas Gerais State. Based on examples of the Preliminary License Process about large sugar cane industry, tried at the Council on Environmental Policy of Triangulo Mineiro e Alto Paranaíba, MG, this paper presents, therefore, the 
procedures of insertion of interdisciplinarity in analyses of environmental licensing proceedings from Minas Gerais State, elucidates its contribution to formulation of new strategies and ways of thinking to assess the environmental impacts and the difficulties to its adoption.

Keywords: Environmental License. Interdisciplinarity. Environmental Planning.

\section{INTRODUÇÃO}

A avaliação de impactos ambientais e o licenciamento de atividades efetiva ou potencialmente poluidoras são estabelecidas pela Política Nacional de Meio Ambiente, de 1981, como dois de seus instrumentos de implantação. No Estado de Minas Gerais, no ano de 1980, a Lei $\mathrm{n}^{\circ} 7.772$ que dispõe sobre a proteção, conservação e melhoria do meio ambiente, no seu artigo $8^{\circ}$, já estabelecia que

A instalação, construção, ampliação ou o funcionamento de fonte de poluição [...] ficam sujeitos a autorização da Comissão de Política Ambiental - COPAM, mediante licença de instalação e de funcionamento, após exame do impacto ambiental e de acordo com o respectivo relatório conclusivo. (Lei 7.772/1980, art. $8^{\circ}$ )

Dessa forma, a partir do início dos anos de 1980, em consonância com a legislação federal e estadual, o licenciamento ambiental passa a ser um dos principais instrumentos de controle ambiental no Estado, uma vez que teoricamente deveria propiciar ações preventivas em relação a empreendimentos que iriam se instalar e, além dessas, medidas corretivas e compensatórias para aqueles em operação.

Em Minas Gerais, o licenciamento ambiental compreende três fases: a primeira, denominada Licença Prévia, é focada na viabilidade ambiental do empreendimento, em termos conceituais, tomando como base a análise do Estudo de Impacto Ambiental (EIA) e respectivo Relatório de Impacto Ambiental (RIMA), para projetos de maior complexidade, ou do Relatório de Controle Ambiental (RCA), para projetos mais simples.

A segunda fase, Licença de Instalação, é centrada nos projetos executivos de controle ambiental, na análise da sua eficiência para os efeitos relatados na fase anterior, tomando como base o Plano de Controle Ambiental (PCA). A partir da concessão dessa licença, o empreendimento fica autorizado a ser instalado.

A terceira fase, Licença de Operação, baseia-se propriamente na verificação, por parte do órgão licenciador, da instalação correta das medidas de controle dos impactos ambientais previstos nas fases anteriores.

Para os empreendimentos já em operação, o licenciamento ambiental é efetuado em uma única fase, denominada licenciamento de operação em caráter corretivo, no qual os empreendedores apresentam os estudos pertinentes, referentes aos efeitos ambientais da operação de sua atividade, e respectivas medidas mitigadoras e compensatórias, quando for o caso.

Até 2003, todo o processo de licenciamento ambiental era realizado, de modo centralizado, em Belo Horizonte, e de forma segmentada, em cada um dos entes vinculados à Secretaria Estadual de Meio Ambiente e Desenvolvimento Sustentável - SEMAD, responsável pela análise dos impactos ambientais respectivos às suas áreas de atuação. Assim, ao Instituto Estadual de Florestas - IEF cabia a avaliação dos impactos sobre a vegetação e regularização de reservas legais e intervenção em áreas de preservação permanente; ao IGAM - Instituto Mineiro de Gestão das Águas, a análise e concessão do uso dos recursos hídricos, e à FEAM - Fundação Estadual de Meio Ambiente, a avaliação dos impactos concernentes aos resíduos sólidos, ruídos, efluentes líquidos e atmosféricos, provenientes de atividades industriais, minerárias e obras de infra-estrutura.

Em 2003, contudo, a Lei Delegada $n^{\circ}$ 62/2003 ao estabelecer a regionalização de forma unificada das entidades vinculadas à SEMAD, ou seja, da FEAM, IEF e IGAM, e a unificação do licenciamento ambiental, provoca a total modificação do modelo anterior 
de análise, trazendo enormes reflexos à avaliação dos processos de licenciamento, bem como ao Sistema de Meio Ambiente - SISEMA ${ }^{1}$ como um todo.

Nesse sentido, a proposta desse artigo é apresentar as modificações provenientes do processo de regionalização da SEMAD, discorrendo principalmente sobre a implantação da análise interdisciplinar dos processos de licenciamento ambiental, atualmente em vigor no Estado, refletindo sobre os seus aspectos positivos e as dificuldades para a sua implantação.

\section{UM NOVO OLHAR SOBRE A AVALIAÇÃO DE IM- PACTOS AMBIENTAIS: A IMPLANTAÇÃO DA ANÁLISE INTERDISCIPLINAR EM PROCESSOS DE LICENCIAMENTO AMBIENTAL}

A gestão ambiental no Estado de Minas Gerais ganhou contornos mais nítidos a partir de 1980, quando a Lei no 7772/1980 estabelece a Política Estadual de Proteção, Conservação e Melhoria do Meio Ambiente. Essa lei determina que a implantação e operação dos empreendimentos sejam, a partir de então, concedidas por meio da autorização da então Comissão de Política Ambiental - COPAM², após avaliação dos impactos ambientais e respectivo relatório, elaborado pelos órgãos técnicos que a assessoravam, na época a Superintendência de Ecologia e Engenharia Ambiental (SE).

De acordo com a Fundação João Pinheiro - FJP (1996), contudo,

Nos primeiros anos de aplicação da Lei $n^{\circ}$ 7772/1980, a ênfase de atuação do COPAM estava mais nas multas que no licenciamento. Isso ocorria [...] em função da precariedade da estrutura institucional de apoio ao COPAM, que dificultava a execução de procedimentos técnicos inerentes ao licenciamento ambiental, bem como pelo importante papel desempenhado pela mídia na época. As multas divulgadas pela imprensa chamavam a atenção para a atuação do órgão ambiental e davam a ele popularidade. (Fundação João Pinheiro, 1996, p. 27)

Após a Resolução CONAMA 001/86, quando se normatiza o licenciamento ambiental de atividades efetiva ou potencialmente poluidoras, esses sistemas preexistentes de licenciamento se modificam,

[...] não somente no que tange ao seu campo de aplicação (atividades que utilizem recursos ambientais ou que possam causar degradação ambiental, ao invés de atividades poluidoras), mas também quanto ao tipo de análise que passou a ser feita, não mais abrangendo somente emissões de poluentes e sua dispersão no meio, agora incluindo os efeitos sobre a biota, os impactos sociais, etc. (SÁNCHEZ, 2008, p. 81)

Em 1987, é criada a Fundação Estadual de Meio Ambiente - FEAM, que passa a assessorar e executar a análise dos processos de licenciamento ambiental a serem encaminhados ao COPAM, inclusive no concernente à compatibilização das atividades potencialmente degradadoras em áreas de vegetação natural.

Apesar do Instituto Estadual de Florestas - IEF ter sido criado em 1962, por ser vinculado à Secretaria da Agricultura, possuía uma atuação focada na orientação técnica da atividade de reflorestamento da iniciativa privada, consonante com as diretrizes federais que incentivavam o reflorestamento, tendo uma contribuição, nessa época, muita restrita no que tange à conservação da vegetação do Estado.

Apenas a partir do início dos anos de 1990, com a Lei Florestal mineira $n^{\circ} 10561 / 91$, é que o IEF passa a ter uma contribuição mais efetiva na políti-

\footnotetext{
${ }^{1}$ O SISEMA, conforme Lei Delegada no $125 / 2007$, é integrado pela Secretaria de Estado de Meio Ambiente e Desenvolvimento Sustentável - SEMAD, o Conselho Estadual de Política Ambiental - COPAM, o Conselho Estadual de Recursos Hídricos - CERH, a Fundação Estadual de Meio Ambiente - FEAM, o Instituto Estadual de Florestas - IEF, o Instituto Mineiro de Gestão das Águas - IGAM, os núcleos de gestão ambiental das secretarias de Estado integrantes do COPAM, a Polícia Ambiental da Polícia Militar de Minas Gerais, os comitês de bacias hidrográficas e as agências de bacias hidrográficas.

${ }^{2}$ Atualmente Conselho de Política Ambiental, de acordo com a Lei no 9514/1987.
} 
ca de conservação do meio ambiente, sendo a partir de então desenvolvidas atividades de controle da exploração florestal, regularização de reserva legal e de intervenção em áreas de preservação permanente nas propriedades rurais.

A gestão dos recursos hídricos era de competência do Departamento de Recursos Hídricos $\mathrm{DRH}^{3}$, vinculado à Secretaria de Minas e Energia, cujas outorgas eram concedidas tendo como base a sua análise quantitativa.

Dessa forma, a gestão ambiental do Estado, até meados dos anos de 1990, ocorria de forma desarticulada, em órgãos vinculados a diferentes Secretarias de Estado, cujos objetivos também eram diferenciados.

Em 1995, a Lei 11903/95 cria a Secretaria de Estado de Meio Ambiente e Desenvolvimento Sustentável, aonde são integrados a FEAM e o IEF, e um ano depois o DRH. Inicia-se então uma nova fase, havendo uma busca pela gestão ambiental integrada. Contudo, no tocante à análise dos processos de licenciamento, mantém-se a visão fragmentada e parcial, conforme FIGURA 1. Assim, se relacionados às atividades industriais, minerárias e obras de infra-estrutura, a análise era efetuada pelos técnicos da FEAM; caso se referisse à atividade agrícola, intervenção em área de vegetação ou regularização de reserva legal, do IEF, e processos relacionados ao uso dos recursos hídricos eram da competência do IGAM, antigo DRH. Após a vistoria e conclusão da análise técnica, elaborava-se o Parecer Técnico (PT). O processo então seguia para análise e elaboração de Parecer Jurídico (PJ), sendo então encaminhados ao COPAM, para servirem de base ao deferimento ou indeferimento da referida licença.

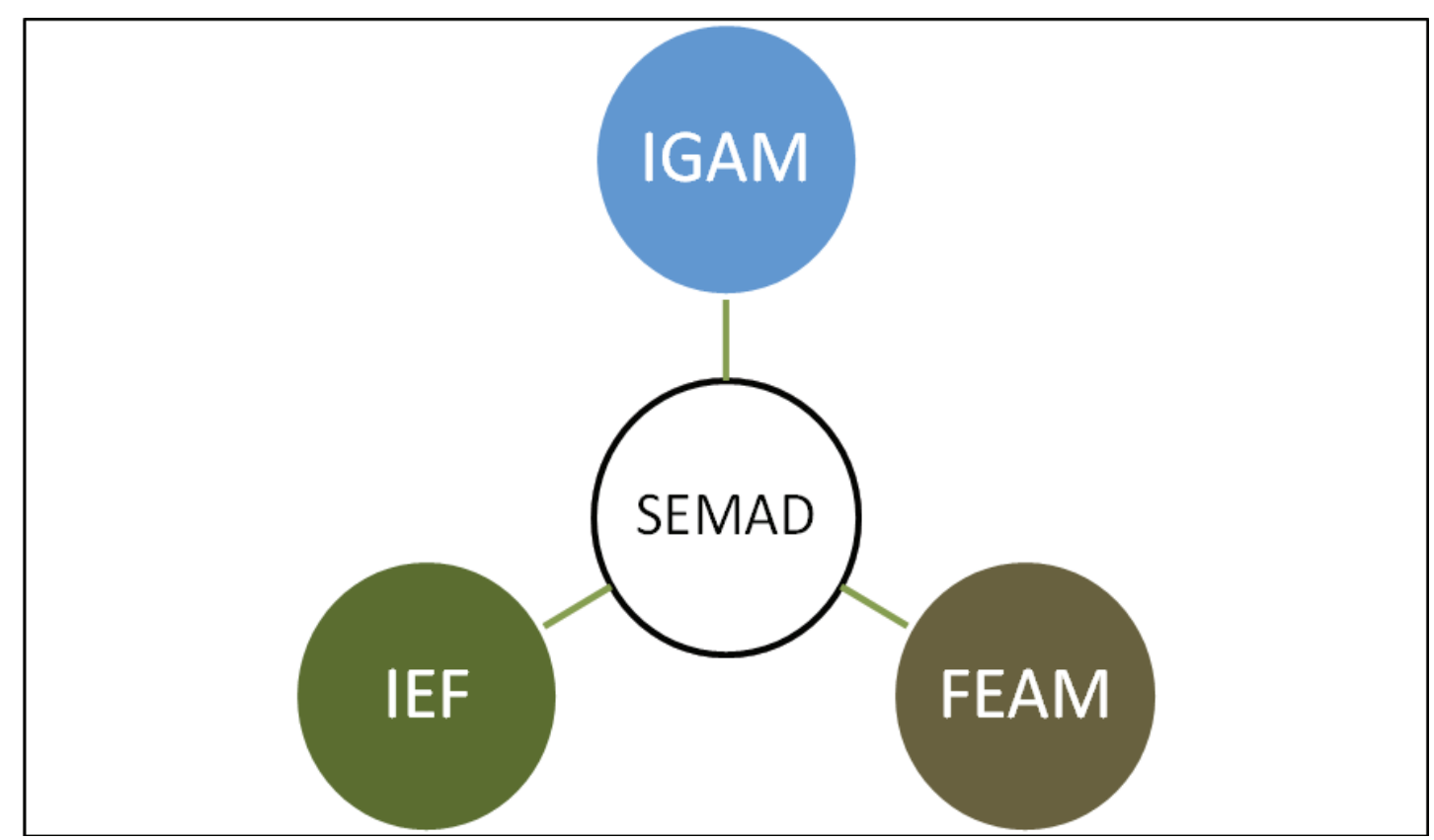

FIGURA 1: Abordagem disciplinar da análise dos processos de regularização ambiental ${ }^{4}$ efetuada pelas diferentes instituições vinculadas à SEMAD, antes de 2003.

Autora: Gelze Serrat S. C. Rodrigues, 2010

\footnotetext{
${ }^{3}$ A Lei 12584/1997 altera a denominação de Departamento de Recursos Hídricos do Estado de Minas Gerais para Instituto Mineiro da Gestão das Águas - IGAM.

${ }^{4}$ No âmbito do Estado de Minas Gerais, os processos de regularização ambiental abrangem o licenciamento ambiental, a autorização ambiental de funcionamento, a outorga de direito de uso de recurso hídrico e a autorização para exploração florestal.
} 
A interlocução entre tais entes (FEAM, IEF e IGAM) continuava praticamente inexistente, ficando os seus técnicos subjugados a um ordenamento reducionista das análises, aonde por meio de uma lógica dedutivo-indutiva, chegavam às suas conclusões, expostas nos pareceres técnicos apresentados ao COPAM.

O instrumento de aplicação da Política de Meio Ambiente - licenciamento ambiental - transformase, assim, em grande parte em um simples processo burocrático. A análise parcial e pontual resultava em ações pulverizadas e pouco relevantes em termos de manutenção ou melhoria da qualidade ambiental das realidades locais e regionais, aonde os empreendimentos pretendiam ser instalados ou encontravam-se em operação.

Sob outra ótica, essa ineficiência também era colocada em discussão pelos empreendedores, considerando os longos prazos para a obtenção de uma licença ambiental no Estado. Conforme Paula, “[...] em 2002, havia só na FEAM - Fundação Estadual de Meio Ambiente um total aproximado de seis mil processos de licenciamento ambiental à espera de análise técnica [...]" (PAULA, 2007, p. 22)

Aliado ao problema da fragmentação do processo de avaliação dos impactos ambientais e da morosidade para obtenção das licenças ambientais, a centralização de todos os procedimentos do processo de licenciamento, desde sua formalização até a expedição da licença propriamente dita, em Belo Horizon- te, apresentava-se como outro entrave. Tal fato, além de dificultar a regularização ambiental dos empreendimentos mais distantes da capital, quer pela dificuldade de acesso dos requerentes, quer pela dificuldade da locomoção dos técnicos, também se constituía em um óbice para a participação efetiva dos diversos atores da sociedade na discussão do encaminhamento da política pública de meio ambiente na sua região.

Todo esse quadro acabou por resultar em um descontentamento geral, seja de empreendedores, insatisfeitos com a ineficiência dos serviços prestados pelo Sistema Estadual de Meio Ambiente e Recursos Hídricos - SISEMA, seja de outros setores da sociedade civil, que não tinham voz nas decisões tomadas pelo COPAM, em Belo Horizonte.

Assim, a necessidade da reestruturação da gestão ambiental impunha-se de forma premente, a fim de se tentar atingir a efetiva conservação e melhoria da qualidade ambiental do Estado e atender as demandas empresariais. Nessa direção e procurando propor um modelo que desse resposta ao descontentamento da sociedade, em 2003, inicia-se a regionalização do COPAM, culminando na criação de dez Unidades Regionais Colegiadas - URCs apoiadas técnica e administrativamente pelas respectivas Superintendências Regionais de Meio Ambiente e Desenvolvimento Sustentável - SUPRAMs, conforme QUADRO 1.

A determinação da área de abrangência das SUPRAMs levou em consideração as regiões de planejamento do Estado, a malha viária e as bacias hi-

\begin{tabular}{|l|l|c|}
\hline \multicolumn{1}{|c|}{ Regional } & \multicolumn{1}{c|}{ M unicípio sede } & No. de municípios atendidos \\
\hline Alto São Francisco & Divinópolis & 55 \\
\hline J equitinhonha & Diamantina & 56 \\
\hline L este M ineiro & Governador Valadares & 135 \\
\hline Norte de M inas & M ontes Claros & 91 \\
\hline Noroeste de M inas & Unaí & 21 \\
\hline Sul de M inas & Varginha & 178 \\
\hline Triângulo M ineiro e A lto Paranaíba & U berlândia & 67 \\
\hline Zona da M ata & Ubá & 162 \\
\hline Rio Paraopeba & Belo Horizonte & 44 \\
\hline Rio da Velhas & Belo Horizonte & 44 \\
\hline
\end{tabular}

QUADRO 1: Unidades Regionais Colegiadas do COPAM/MG. Fonte: Minas Gerais. Decreto Estadual nº 44667/2007. 
drográficas, e, de acordo com Paula, “[...] a escolha das cidades-sede levou em conta a conjugação dos seguintes fatores: importância regional, facilidades de acesso, representatividade política, nível de desenvolvimento e questões culturais" (PAULA, 2007, p. 35).

Apesar de desde 1977, o sistema de administração ambiental do Estado de Minas Gerais contar com a participação da sociedade civil através do COPAM, órgão normativo, colegiado, consultivo e deliberativo, subordinado à SEMAD, composto paritariamente por representantes do Poder Público, sociedade civil e setor produtivo, a realização das reuniões em Belo Horizonte, dificultava a efetiva participação da população das diversas regiões do Estado nas decisões sobre a política ambiental regional, as quais ficavam centralizadas na capital.

Ao estabelecer, no Decreto ${ }^{\circ} 44667 / 2007$, que as URCs são, assim como o COPAM, órgãos deliberativos e normativos, composta por vinte membros titulares, dos quais 50\% são representes do Poder Público e $50 \%$ representantes da sociedade civil, o Estado propicia a participação mais efetiva dos cidadãos locais nas decisões sobre as questões ambientais de sua região.

Concomitantemente ao processo de regionalização, a metodologia de análise dos processos de licenciamento do Estado de Minas Gerais se modifica. Passa a ser implantada a denominada AIPRA - Análise Interdisciplinar dos Processos de Regularização Ambiental, pela qual se pretende, por meio da integração dos profissionais das áreas técnica e jurídica das três casas - FEAM, IEF e IGAM, nas SUPRAMs, inserir o uso de uma metodologia sistêmica, onde os impactos ambientais dos empreendimentos apontados nos estudos ambientais ${ }^{5}$ apresentados ao órgão estadual passariam a ser avaliados de forma interdisciplinar.

Com esse propósito, inicia-se um processo de implantação de modificações nos aspectos conceituais, gerenciais e técnico-operacionais, procurando-se apontar a necessidade da incorporação de novas pers- pectivas e procedimentos de análise, a fim de integrar os vários aspectos ambientais concernentes à avaliação dos impactos ambientais potenciais ou efetivamente provocados pela instalação ou operação dos empreendimentos.

Por meio da discussão de conceitos, tais como multidisciplinaridade, interdisciplinaridade, transdisciplinaridade, visão sistêmica do ambiente, holismo, complexidade e sustentabilidade, procura-se inserir uma mudança na forma de pensar sobre o ambiente.

Por meio de mudanças gerenciais, são incorporadas na rotina do escritório, reuniões semanais nas SUPRAMs, onde toda a equipe - técnicos, diretores e superintendente - discute as táticas e atividades da semana vinculadas aos processos em análise ou pertinentes à gestão ambiental da região, planeja as vistorias, racionaliza as suas viagens, debate problemas ou questões ambientais vivenciadas ou de que se teve conhecimento, apresenta novas normas ou leis, bem como são distribuídos os processos para seus respectivos gestores.

Além disso, passa a haver avaliações e auditorias, onde são apresentados os resultados de gestão das SUPRAMs, em relação às metas que devem ser atingidas, definidas no Acordo de Resultados firmado com o governo estadual.

O Acordo de Resultados, conforme a Lei Estadual 17.600/2008, é um contrato de gestão onde são definidos os resultados esperados em cada setor governamental, os quais são repassados para cada órgão e seus respectivos servidores, na forma de metas, as quais se atingidas são recompensadas por um conjunto de autonomias gerenciais, financeiras e pagamento de prêmio por produtividade aos servidores.

Sob o aspecto técnico-operacional, todos os processos de regularização ambiental passam a ser formalizados nas respectivas SUPRAMs, os quais devem conter as informações necessárias à avaliação dos impactos ambientais do empreendimento (FIGURA 2).

É criada a figura do gestor de processos, res-

\footnotetext{
${ }^{5}$ Conforme Resolução CONAMA n ${ }^{\circ}$ 237/1997, estudos ambientais “[...] são todos e quaisquer estudos relativos aos aspectos ambientais relacionados à localização, instalação, operação e ampliação de uma atividade ou empreendimento, apresentado como subsídio para a análise requerida, tais como: relatório ambiental, plano e projeto de controle ambiental, relatório ambiental preliminar, diagnóstico ambiental, plano de manejo, plano de recuperação de área degradada e análise preliminar de risco.” (Res. CONAMA 237/97, art $1^{\mathrm{o}}$, inciso III)
}

Sociedade \& N atureza, U berlândia, 22 (2): 267-282, ago. 2010 


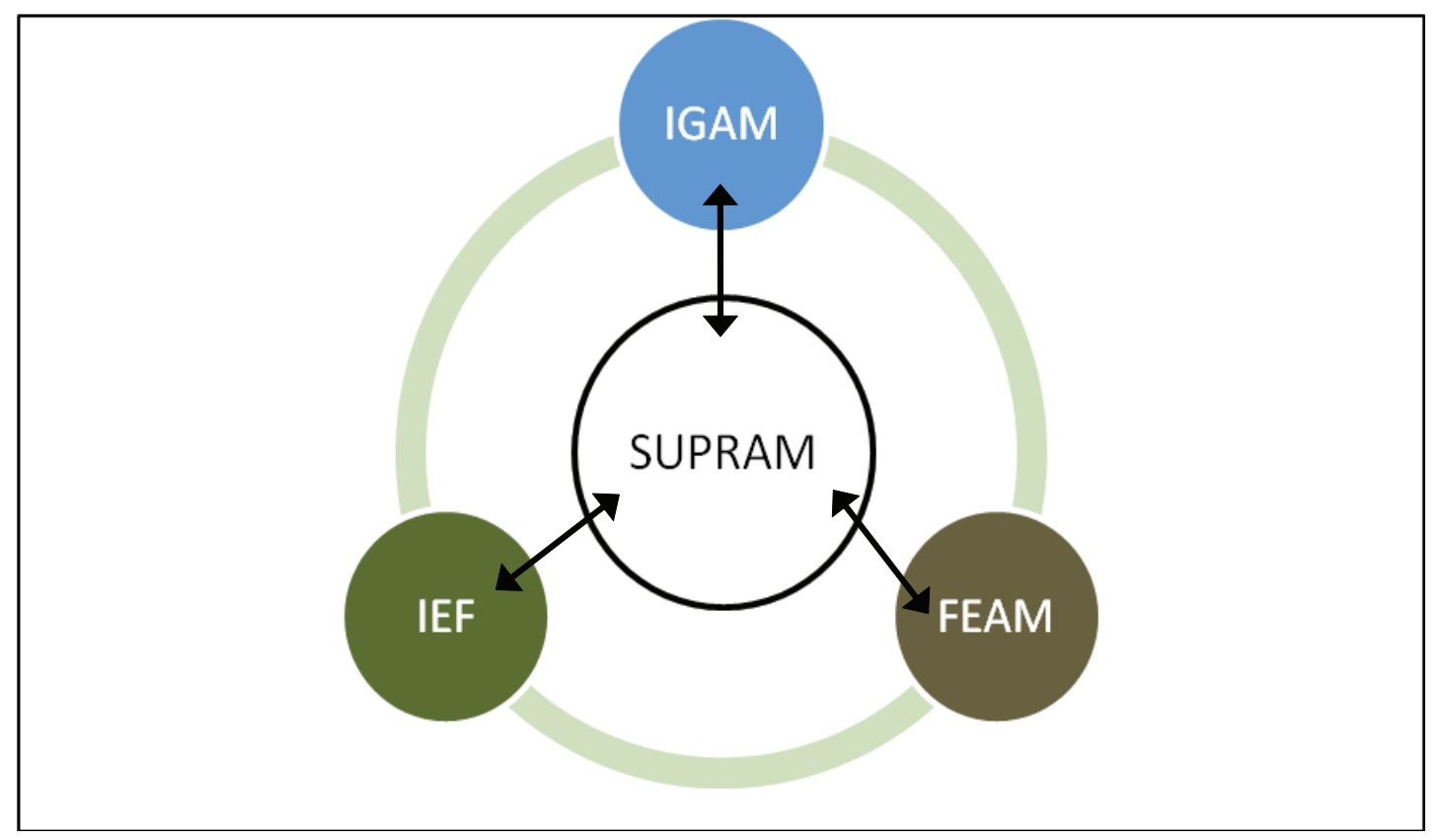

FIGURA 2: Abordagem interdisciplinar da análise dos processos de regularização ambiental efetuada pelas diferentes instituições vinculadas à SEMAD, após implantação da AIPRA.

Autor: Gelze Serrat de S. C. Rodrigues, 2010.

ponsável pela definição e gerenciamento da equipe de analistas ambientais que deverão fazer a sua análise interdisciplinar, organização da vistoria ao empreendimento, solicitação de informações complementares necessárias à continuidade da análise do processo e elaboração do Parecer Único (PU), que será encaminhado à URC, para deferimento ou indeferimento da licença solicitada, os quais passam a ser executados e elaborados de forma integrada, inclusive com a avaliação jurídica, desde o início da análise do processo.

Buscando-se a efetivação dessas mudanças estruturais e sua internalização, os servidores das SUPRAMs passam, a partir de 2006, por intenso programa de capacitação e treinamento,

[...] visando a integração das ações e trabaIhos, construção de conceitos, nivelamento de conhecimentos, quebra de paradigmas - para viabilizar o sistema interdisciplinar de ação - e a construção e instituição de normas e procedimentos com o intuito de acelerar, sem perda de qualidade dos estudos e análises, o licenciamento ambiental no Estado. (PAULA, 2007, p. 19-20)
Essa provocação em direção ao novo, essa perturbação do instituído, do aceito, no entanto, incomoda, produz reações de negação e rejeição, ao mesmo tempo em que traz novas iniciativas, produz inquietações sobre diferentes formas de se entender, analisar o ambiente e interagir com os setores envolvidos na regularização ambiental dos empreendimentos, criando conflitos e questionamentos diferenciados, como poderá ser observado a seguir.

\section{CONFLITOS ENTRE NOVOSE VELHOS PARADIGMAS}

A fragmentação da análise dos processos de licenciamento ambiental está relacionada com a concepção de conhecimento, dominante desde o século XVI, que buscava a revelação de leis que regem os fenômenos e o estabelecimento de verdades, por meio de quatro grandes princípios: o da ordem, que rege a natureza e o mundo, visto como uma máquina perfeita, cujo conhecimento pleno permitiria a previsão dos conhecimentos futuros; o da separação, que leva à especialização das disciplinas e à sua falta de integração; o da redução, de onde por meio das partes se poderia chegar ao conhecimento do todo; e, o da lógi- 
ca dedutivo-reducionista clássica, pela qual qualquer contradição deveria ser eliminada.

É certo que tais procedimentos possibilitaram a construção de conhecimentos e o acesso a conquistas notáveis, contudo são incapazes de tratar e levar ao entendimento de certas questões colocadas atualmente pela sociedade contemporânea, como as ambientais. Assim, novas abordagens vão se constituindo, na tentativa de integrar a percepção fragmentada da realidade que nos foi legada pelo desenvolvimento das ciências modernas.

Uma dessas abordagens é a interdisciplinar, a qual pode ser entendida de várias formas, desde a simples justaposição de disciplinas (na verdade uma multidisciplinaridade) até a fusão de conceitos e procedimentos (transdisciplinaridade), justamente por ser utilizada em espaços diferenciados e com propósitos diferentes.

Conforme Pombo (2005), o que é interessante ser retido, ao invés de procurar uma conceituação fechada, é que nessas novas abordagens, sejam elas a multi, a inter ou a transdisciplinaridade, o que se procura é o rompimento do caráter estanque da disciplinarização.

Nesse sentido, temos que a avaliação de impactos ambientais efetuada separadamente nos diferentes órgãos técnicos que compõem o SISEMA, apoiavase no paradigma da separação das ciências modernas, seguindo a lógica de que ao final, somando-se todas as análises, obter-se-ia o panorama geral dos efeitos derivados das diversas atividades a serem instaladas ou em operação sobre o ambiente.

Por meio de uma postura personalista e fragmentada de análise, um único técnico, ou técnicos, geralmente da mesma área de formação, detinha o controle de todas as informações acerca de um determinado processo ou de parte dele, sendo a avaliação de impactos ambientais baseada no conhecimento específico da sua especialização.

Considerando-se a expansão do setor sucroalcooleiro, na mesorregião do Triângulo Mineiro e Alto
Paranaíba, e a consequente demanda de solicitação de Licenças Prévias, bem como por ser nessa fase onde ocorre a avaliação da viabilidade ambiental do empreendimento, optou-se por tomar como base exemplificativa para demonstração das diferenças entre as análises - fragmentada e interdisciplinar — dos processos de licenciamento ambiental os Pareceres Técnicos e Únicos referentes à Licença Prévia de empreendimentos sucroalcooleiros, classes 05 e $06^{5}$, julgados pelo COPAM Triângulo Mineiro e Alto Paranaíba, desde a data de sua primeira reunião (11/08/2006) até a $67^{\mathrm{a}}$ Reunião (11/06/2010).

Nesse período, do total de oito processos julgados, conforme QUADRO 2, 06 foram baseados em Pareceres Técnicos de processos ainda formalizados em Belo Horizonte, no período de transição para o novo modelo, e 02 em Pareceres Únicos, formalizados na SUPRAM, seguindo o modelo interdisciplinar.

Todos os Pareceres Técnicos foram elaborados por um único analista ambiental, com formação em engenharia química, da FEAM, mas já contando na vistoria de 04 empreendimentos com o auxílio de funcionários do IEF. Contudo, em um dos pareceres observa-se a dificuldade em se conciliar os horários dos técnicos das três casas, quando há a afirmação de que

A despeito da orientação de análise em conjunto das 3 agendas nos processos de licenciamento ambiental, foi solicitada a disponibilização de um técnico do IEF e outro do IGAM para acompanhamento de vistoria conjunta (...). Ressalta-se que esta vistoria em conjunto não foi realizada devido a conflitos de agendamento. (SEMAD, Parecer GEDIN nº 07/2008, 2008, p. 495)

$\mathrm{Na}$ análise dos Pareceres Técnicos, constata-se que o foco está no processo operacional das usinas, nos aspectos relacionados à emissão dos efluentes líquidos, emissões atmosféricas e produção de resíduos sólidos decorrentes da atividade industrial e nas res-

\footnotetext{
${ }^{6}$ A DN COPAM 74/2004 estabelece em seu artigo 16, inciso V, que empreendimento classe 05 são aqueles que possuem "grande porte e médio potencial poluídos ou médio porte e grande potencial poluidor" e no inciso VI, que empreendimentos classe 06 são aqueles que possuem "grande porte e grande potencial poluidor", sendo que o porte é determinado nas listagens apresesentadas nessa DN, de acordo com as características do empreendimento.
}

Sociedade \& N atureza, U berlândia, 22 (2): 267-282, ago. 2010 


\begin{tabular}{|l|l|l|l|}
\hline $\begin{array}{l}N^{\text {o }} \text { Reunião COPAM/ } \\
\text { data de realização }\end{array}$ & $\begin{array}{l}\mathrm{N}^{\text {o }} \text { do Processo de } \\
\text { Licença Prévia }\end{array}$ & Empreendimento & M odelo de Parecer \\
\hline $\begin{array}{l}37^{\mathrm{a}} \\
11 / 10 / 2007\end{array}$ & $15925 / 2006 / 001 / 2007$ & Usina A raguari Ltda. & Parecer Técnico - FEAM \\
\hline $\begin{array}{l}38^{\mathrm{a}} \\
09 / 11 / 2007\end{array}$ & $10314 / 2006 / 001 / 2007$ & $\begin{array}{l}\text { Cabrera Central Energética A çúcar e } \\
\text { Álcool Ltda. }\end{array}$ & Parecer Técnico - FEAM \\
\hline $\begin{array}{l}38^{\mathrm{a}} \\
09 / 11 / 2007\end{array}$ & $2327 / 2007 / 001 / 2007$ & $\begin{array}{l}\text { Cia. Energética de Acúcar e Álcool } \\
\text { Vale do Tijuco L tda. }\end{array}$ & Parecer Técnico - FEAM \\
\hline $\begin{array}{l}38^{\mathrm{a}} \\
09 / 11 / 2007\end{array}$ & $10203 / 2006 / 001 / 2007$ & Usina Cerradão L tda. & Parecer Técnico - FEAM \\
\hline $\begin{array}{l}40^{\mathrm{a}} \\
14 / 03 / 2008\end{array}$ & $12616 / 2006 / 001 / 2007$ & $\begin{array}{l}\text { Usina Tupaciguara A çúcar eA A lcool } \\
\text { Ltda. }\end{array}$ & Parecer Técnico - FEAM \\
\hline $\begin{array}{l}40^{\mathrm{a}} \\
14 / 03 / 2008\end{array}$ & $12914 / 2006 / 001 / 2007$ & Fle Empreendimentos L tda. & Parecer Técnico - FEAM \\
\hline $\begin{array}{l}42^{\mathrm{a}} \\
11 / 04 / 2008\end{array}$ & $04978 / 2007 / 001 / 2007$ & Cia. Energética Vale do São Simão & Parecer Único - SUPRAM \\
\hline $\begin{array}{l}46^{\mathrm{a}} \\
08 / 08 / 2008\end{array}$ & $04940 / 2006 / 004 / 2008$ & $\begin{array}{l}\text { Crystalsev Comercio e Represen- } \\
\text { tação L tda. Santa Vitória A çúcar e } \\
\text { Álcool S/A. }\end{array}$ & Parecer Único - SUPRAM \\
\hline $\begin{array}{l}53^{\mathrm{a}} \\
12 / 03 / 2009\end{array}$ & $\begin{array}{l}\text { União M inas A groindustrial A çúcar e } \\
\text { Álcool Ltda. }\end{array}$ & Parecer Técnico - FEAM \\
\hline
\end{tabular}

QUADRO 2: Pareceres de processos de Licença Prévia de empreendimentos sucroalcooleiros, classes 5/6, julgados no COPAM Triângulo Mineiro e Alto Paranaíba, no período de 11/08/2006 a 11/06/2010.

Autora: Gelze S. S. C. Rodrigues, 2010.

pectivas medidas mitigadoras propostas, condizentes com a formação do responsável pelos Pareceres. Contudo, a análise da viabilidade locacional do empreendimento, objetivo principal da licença prévia, exige a avaliação dos aspectos bióticos e sócio-econômicos, a qual, nesses pareceres, se efetiva a partir de informações do senso comum e disponibilizadas na mídia. Mesmo nos casos onde os estudos ambientais não apresentam o diagnóstico da fauna da área onde será implantado o empreendimento, esse tema é avaliado a partir da inferência nos estudos apresentados por outras usinas, como pode ser observado no excerto a seguir:

Em relação à fauna, não há qualquer comentário no RCA nesse sentido. Entretanto, os aspectos bióticos que constatam dos estudos efetuados por outras usinas em seus respectivos licenciamentos ambientais, inclusive EIA/ RIMA, (...) apontam a presença de Lobo-guará
(Chyscocyon brachyurus). Presença esta ameaçada segundo reportagem do MGTV do dia 27-8-2007 relativa ao aumento desses animais no cativeiro de Uberaba devido às queimadas $e$ acidentes de trânsito na região. Portanto, é plausível considerar sua presença também na área de influência desse empreendimento. (SEMAD, Parecer GEDIN $n^{\circ}$ 158/2007, 2007, $p$. 519)

Outro aspecto importante, é que os Pareceres Técnicos não discorrem sobre as condições de conservação das Áreas de Preservação Permanente e das Reservas Legais, considerando-se ser objeto de competência do IEF.

Em relação ao uso de recursos hídricos, conforme relatado nos Pareceres, o procedimento adotado era a realização de uma reunião com os técnicos do IGAM, os quais emitiam um parecer acerca da disponibilidade hídrica, considerando o uso pretendido 
pelo empreendimento, os outros usos já outorgados e a vazão do curso d'água.

Nos Pareceres Técnicos a análise dos aspectos socioeconômicos reduz-se a dois parágrafos, onde é salientado que os estudos ambientais se limitam a enfatizar os impactos positivos da inserção de tal unidade na região, considerando a geração de postos de trabalho, aumento da arrecadação de impostos e aumento do fluxo do comércio local. Apesar de não ser feita referência a dados socioeconômicos dos municípios da área de influência do empreendimento ou a pesquisas de percepção da sua população em relação à implantação dos empreendimentos, é mencionado em todos Pareceres Técnicos analisados que

Entretanto, existe de modo geral um descontentamento da população da região do Triângulo Mineiro, quanto ao crescimento desordenado desta atividade industrial, percebida por meio das várias reportagens que vêm sendo veiculadas na mídia; existe também a possibilidade de monocultura da cana-de -açúcar na região do triângulo [sic], cujos reflexos como em qualquer cultura são maléficos ao ambiente e a economia do país. (SEMAD, Parecer GE$D I N n^{\circ}$ 253/2007, 2007, p. 283)

Concluindo-se, no entanto que

(...) essas questões fogem ao escopo deste licenciamento, tendo em vista que ao permitir que o empreendimento se instale no local, o município deveria possuir toda a infra-estrutura em termos de vias de acesso, cuja implantação, pavimentação ou melhoramento de rodovias são objeto de licenciamento especifico (...), moradias, saúde e educação para o aumento da população no período de safra. (IDEM)

Percebe-se, assim, que a disciplinarização e a valorização das partes em detrimento do todo, negligencia as relações entre os diversos componentes do ambiente, bem como as suas relações com o universo do qual são partes integrantes, sendo incapazes, ou parcialmente capazes, de oferecer respostas aos questionamentos em relação à avaliação de impactos ambientais causados pela implantação dos empreendimentos.

A avaliação de impactos ambientais implica em levar em consideração a complexidade dos sistemas envolvidos, a multiplicidade de seus componentes (físicos, químicos, biológicos, ecológicos, humanos e sociais), a não-linearidade dos fenômenos subjacentes bem como a estrutura espacial e as diferentes escalas espaciais e temporais de suas causas e efeitos.

Tal preocupação pode ser observada nos dois Pareceres Únicos analisados, elaborados por equipes multidisciplinares, compostas por engenheiros químicos, agrônomos, engenheiro de minas e ambiental, geógrafo, biólogo e advogado, o que resulta em uma análise mais profunda do conjunto de componentes do ambiente e potencialmente possíveis de serem impactados pela implantação do empreendimento, indo além da análise dos parâmetros dos efluentes líquidos, emissões atmosféricas e resíduos sólidos a serem emitidos pela indústria.

Diferentemente dos Pareceres Técnicos, é apresentado o grau de conservação das Áreas de Preservação Permanente e da Reserva Legal e em relação à fauna, são descritas as espécies observadas e presentes nas listas dos estudos ambientais, sendo que quando insuficientes, há a solicitação de estudos mais detalhados, conforme descrito a seguir.

Quanto a Fauna realizou-se um estudo preliminar da fauna local utilizando-se de três grupos representativos (répteis, aves e mamíferos). Tal estudo destacou a existência de espécies típicas da região, por meio de entrevistas e/ou visualização, como se segue [...]

[...]

Os efeitos dos impactos sobre a fauna podem ser mitigados pela recuperação das matas ciliares e pela manutenção das reservas florestais. Vale lembrar que a conservação e recuperação destas áreas ampliará a área de deslocamento de algumas espécies (como onças, antas e veados) e fará a conectividade com um importante ecossistema que é a mata ciliar da represa de São Simão. No entanto, não se descarta a necessidade de um monitoramento sobre a herpetofauna, mastofauna e ornitofau- 
na local, afim de melhor caracterizar os grupos remanescente no ambiente. (SEMAD, Parecer Único $n^{\circ}$ 183115/2008, 2008, p. 14-15)

Em relação aos aspectos socioeconômicos são apresentados os dados demográficos e econômicos dos municípios das Áreas de Influência Direta e Indireta do empreendimento e avaliados os impactos positivos e negativos do empreendimento, sendo salientadas informações acerca da necessidade da adequabilidade da infra-estrutura do município para a recepção da mão-de-obra necessária para a instalação e operação da indústria, como se pode verificar no trecho abaixo.

Os alojamentos serão instalados na cidade de Santa Vitória, em local escolhido em conjunto com a Prefeitura Municipal, levando em consideração o planejamento da expansão da cidade (Plano Diretor), em terreno onde não haja a necessidade de supressão vegetal e de movimentação excessiva de terra. O local deverá ser provido de rede de abastecimento de água, rede elétrica, coleta de lixo e que apresente ainda, condição para a instalação de fossas sépticas elou para a construção de rede de coleta e tratamento dos efluentes sanitários. (SEMAD, Parecer Único $n^{\circ} 183115 / 2008,2008, p .18$ )

Dessa forma, percebe-se que a adoção do enfoque interdisciplinar, mobilizando em diferentes graus de intensidade, técnicos de diferentes áreas do saber, propicia a inserção da análise de processos biofísicos e sociais de diferentes ordens de materialidade e esferas de racionalidade nos pareceres e a utilização de procedimentos mais adequados para a análise dos processos de licenciamento ambiental.

Sob outra ótica, Lenoir e Hasni, em 2004, ressaltam a existência de três lógicas distintas na adoção da interdisciplinaridade, oriundas de três culturas diferentes, a francesa, a norte-america e a brasileira. A de origem francesa, ou da lógica racional, tem um caráter reflexivo e crítico, orientada para a unificação das disciplinas e a discussão sobre as conexões dos saberes científicos. A interdisciplinaridade norteamericana está focada na lógica instrumental, na “[...] busca de respostas operacionais a perguntas feitas pela sociedade" (LENOIR e HASNI, 2004, p. 175). E, a brasileira, a qual destaca o papel fundamental do agente da abordagem interdisciplinar, cuja prática estaria baseada em quatro princípios: humildade, coerência, expectativa e audácia, que levariam às trocas dos saberes e à colaboração.

Apesar dos autores refletirem sobre as diferentes lógicas subjacentes na perspectiva interdisciplinar, nos espaços escolares, acreditamos que a sua reflexão possa ser expandida para a compreensão da prática interdisciplinar em outros espaços. Nesse contexto, verifica-se que a inserção da perspectiva interdisciplinar no SISEMA, segue as três lógicas apresentadas por Lenoir e Hasni (2004): uma, relacionada ao saber, onde há uma busca pela integração das diferentes disciplinas na avaliação dos impactos ambientais e abertura de espaços para a discussão de conceitos. Outra, vinculada à lógica instrumental, na procura de procedimentos que levem à análise interdisciplinar. E, a terceira, focada no indivíduo, na atitude interdisciplinar que o analista ambiental deve desenvolver, de humildade, inquietude e audácia.

Nessa mesma linha de pensamento, convém observar ainda que apesar da interdisciplinaridade aparecer como uma categoria aparentemente exclusiva do mundo do conhecimento, largamente discutida no âmbito acadêmico e escolar, aos poucos ela vai sendo incorporada nas práticas e discursos do mundo trabalho, principalmente vinculados ao modelo toyotista de produção. Mangini e Mioto (2009) esclarecem que nesse modelo

[...] a interdisciplinaridade é tomada como uma atitude de abertura do sujeito individual ou coletivo (equipe), disposto à: integração, interação, coordenação, colaboração, e à cooperação. Além de disposição e abertura, é fundamental desenvolver uma postura flexivel em face das mudanças, das novidades e das diferenças. $O$ sujeito interdisciplinar (grifo nosso) é um aventureiro que busca ultrapassar as barreiras do conhecimento e inovar, ou seja, ser transdisciplinar. (MANGINI e MIOTO, 2009, P. 212)

Mais adiante, as autoras ressaltam que 
Com a difusão do conceito de interdisciplinaridade, as exigências de trabalho em equipe, competência, polivalência, multifuncionalidade, desespecialização ganham respaldo acadêmico/cientifico, ou seja, base teórico-metodológica." (MANGINI e MIOTO, 2009, p. 212)

Dentro desse contexto, e considerando a impregnação das rotinas de trabalho dos analistas ambientais pela visão especialista e linear de análise de processos de licenciamento ambiental, executada por anos, várias ações foram sendo implementadas pela equipe responsável da AIPRA, na SEMAD, com o intuito da efetiva implantação do novo modelo, relacionadas à(o):

- Conserva Cultural - mesmo conscientes da necessidade de mudar, influências culturais conservadoras pesam nos procedimentos da equipe, exigindo um constante auto-avaliação, no sentido de não permitir que resquícios do antigo modelo, a todo momento, aflorem, turvando a proposta e decisão de romper as velhas estruturas, de mudar;

- Internalização do espírito de equipe - superar o individualismo que está na raiz mesma da cultura nacional é um grande desafio. Além disso, é preciso mudar cabeças no sentido da valorização da humildade profissional, do respeito ao outro, e às opiniões e posições diferentes; da capacidade de ouvir com atenção, mesmo discordando do que se diz;

- Firmar a consciência da necessidade de despersonalização dos processos - vendo-os, sempre como peças de interesse público e objeto de análise e decisão técnica integradas;

- Aperfeiçoamento das ferramentas de suporte - conferindo maior eficiência ao SIAM, aperfeiçoando-se os procedimentos e o sistema de comunicação em apoio a Análise Interdisciplinar;

- Melhorar a gestão administrativa - é urgente e inadiável a melhoria da área meio do SISEMA, eliminando-se ou, pelo menos, reduzindo a burocracia que, ainda, muitas vezes emperra e entrava atividades e ameaça a eficiência técnico - operacional.
- Treinamento e Capacitação - é preciso que os investimentos em capacitação sejam alinhados com as necessidades técnicas e operacionais das equipes das SUPRAMs, garantindo aos profissionais conhecimento para o desenvolvimento de sua atividades;

- Valorização das pessoas - embora esteja-se desenvolvendo um novo modelo de trabalho, aprimorando ferramentas e criando procedimentos, a valorização das pessoas tem que estar em primeiro plano. Afinal, o maior "capital” das instituições são seus colaboradores; - Parcerias com o setor Produtivo, Entidades de Classes, ONG's, Universidades e Demais Órgãos públicos - é impossível falar em pensamento sistêmico, trabalho em rede e interdisciplinaridade sem agregar ao processo as contribuições e demandas dos públicos externos que influenciam, direta ou indiretamente, o trabalho;

- Melhoria contínua do Processo - garantirá a efetividade desse processo uma vez que o dinamismo, a globalização e outros fatores externos o influenciam. O processo deverá se adequar às pressões que lhe serão impostas;

- Comunicação Interpessoal e Institucional ferramenta básica para o sucesso de qualquer projeto. É preciso saber relacionar-se com as pessoas e estar informados sobre as questões mais relevantes da instituição, pois o trabalho depende direta ou indiretamente desses fatores; - Estabelecimento de Redes - as rede de cooperação e troca de experiência entre as Superintendências Regionais de Meio Ambiente, é ferramenta importante para troca de experiências e melhoria constante do processo;

- Compartilhamento de Objetivos - os objetivos da instituição têm de ser conhecidos e internalizados, por todos, para que todos os esforços realizados dentro dela sejam direcionados para seus objetivos comuns;

- Pensamento Sistêmico - assim como a natureza, é preciso entender as inter-relações existentes ao redor e perceber que a harmonia só existe, como ocorre na da natureza, quando todos os elementos estão interligados. 
(SECRETARIA DE ESTADO DE MEIO AMBIENTE E DESENVOLVIMENTO SUSTENTÁVEL DE MINAS GERAIS, s/ data, p. 27 a 29)

Ao mesmo tempo deve-se ressaltar que a proposição de um novo olhar, de uma nova postura e da adoção de um novo modelo de análise implicam em modificações de ordem estrutural, como as que ocorreram a partir da regionalização da SEMAD e da implantação da AIPRA, mas também em mudanças de ordem cognitiva e psicológica dos atores participantes desse processo.

A prática interdisciplinar exige, de fato, o recorte do objeto analisado por meio da ação conjunta e permanente de profissionais vinculados a diferentes disciplinas especializadas. Prática viável, mas difícil, constrangedora, desconfortável, já que obriga a compreender, avaliar, aceitar ou rejeitar procedimentos diferentes daqueles empregados na própria disciplina e muitas vezes não familiares.

Ao mesmo tempo, como ressalta Fazenda $(2008,2006)$, consonante com a perspectiva brasileira de interdisciplinaridade, a abordagem interdisciplinar demanda a adoção por parte do indivíduo de uma atitude interdisciplinar, atitude essa caracterizada pela flexibilidade, solidariedade e cooperação. Assim, no trabalho interdisciplinar e, portanto, em equipe, um dos principais pressupostos é o diálogo.

Diálogo que, no presente caso, deve promover a aproximação e a articulação das diversas especialidades no sentido do aprofundamento do entendimento dos potenciais ou efetivos impactos ambientais causados pelo empreendimento em análise, bem como da determinação das medidas a serem adotadas para a manutenção ou recuperação do equilíbrio de um ambiente.

Tudo isso demanda tempo. Tempo para incorporação de novos conceitos e rotinas de trabalho, tempo para possibilitar a interlocução dos técnicos e para a compreensão das especificidades dos diferentes empreendimentos, tempo para a avaliação integrada dos impactos ambientais, o que contraditoriamente se contrapõe às exigências temporais de concessão das licenças por parte dos empreendedores.

\section{CONSIDERAÇÕES FINAIS}

É inegável que o modelo cartesiano, fragmentado, atomístico e disciplinar de análise de processos de licenciamento ambiental não responde as questões intrínsecas relacionadas à temática ambiental. Contudo, também é indiscutível que esse antigo modelo permitiu o alicerçamento de uma política ambiental estadual, com o desenvolvimento da legislação ambiental mineira e criação dos órgãos ambientais, traduzida na constituição do seu Sistema Estadual de Meio Ambiente e Recursos Hídricos - SISEMA. Proporcionou, ao mesmo tempo, a constituição de um corpo técnico e um conhecimento ambiental rico sobre o Estado, que culminaram no desenvolvimento de parâmetros técnicos e deliberações normativas seguidas até hoje.

O processo de regionalização teve como objetivos descentralizar a tomada de decisão, agilizar e desburocratizar o processo de licenciamento ambiental e promover oportunidades de participação dos diversos atores que desempenham os mais variados papéis na construção de uma política pública de meio ambiente.

Em relação à implantação da análise interdisciplinar dos processos de licenciamento, de acordo com documento produzido pela SEMAD, o que o SISEMA pretendia era

[...] criar em seu corpo técnico [...] uma cultura de flexibilidade mental e operacional, uma postura permanente de curiosidade e investigação em busca do melhor modo de realizar o seu trabalho e de atender os interesses dos empreendedores, que precisam regularizar suas atividades, e os interesses da população, sintetizados no seu direito constitucional a um meio ambiente de qualidade. (SEMAD, s/ data, p. 5/6)

De fato a implantação tanto da regionalização como da análise interdisciplinar teve o grande mérito de descentralizar a análise dos pedidos de licenciamento, dar celeridade à análise dos processos e à concessão das licenças, permitir uma maior participação de outros atores na discussão da política ambiental estadual e promover a interlocução dos técnicos de diferentes áreas, mesmo que muitas vezes de modo 
superficial. Entretanto, contraditoriamente, impôs a mesma lógica produtivista das corporações privadas, regulando o trabalho técnico por meio da aceleração de suas rotinas, estabelecimento de metas relacionadas ao número de pareceres de processos de licenciamento que devem ser encaminhados para julgamento no COPAM e imposição de procedimentos ainda não absorvidos integralmente pelos técnicos.

Associadamente, os baixos salários recebidos pelos servidores, estimulam a evasão dos profissionais já capacitados pela AIPRA, em direção a outras oportunidades no mercado de trabalho, sendo substituídos por outros profissionais, muitas vezes sem a visão interdisciplinar e sem passarem por um processo de qualificação voltado para a sua utilização. Tudo isso acaba se constituindo em um grande revés ao novo modelo implantado.

Outra questão que se coloca é que apesar da investigação das questões ambientais implicar na necessidade do enfoque interdisciplinar, mobilizando em diferentes graus de intensidade diversas áreas de conhecimento, em alguns casos, como bem observa Leff (2002), a interdisciplinaridade ao integrar processos de diferentes naturezas - biológica, física, social e econômica - pode também cair em um reducionismo de análise, caso essas interlocuções sejam feitas de modo inadequado.

Assim, apesar do enfoque interdisciplinar ser enriquecedor e mesmo necessário à análise dos processos de licenciamento, completando a percepção dos fenômenos e revelando as suas interrelações, a especificidade da formação de cada profissional não deve ser diluída ou reduzida, a ponto de se pensar que qualquer técnico possa analisar temas de qualquer natureza, ou de que a flexibilidade e abertura a novos conhecimentos the promoverão a formação suficiente para assumir as competências profissionais de áreas de conhecimento diversas da sua.

$\mathrm{O}$ autêntico trabalho interdisciplinar, assim,se dá a partir do momento que técnicas e métodos das várias áreas de conhecimento se abrem para a interlocução e para a formulação de novos procedimentos de análise, o que foi propiciado pelo AIPRA, mas também demanda discussão, reflexão, tempo, reunião de profissionais capazes de dialogar sobre a problemática apresentada e dispostos a colaborar. O seu início já foi despontado, contudo consideramos que para sua consolidação e manutenção, várias ações são necessárias, tais como:

a) a continuidade das capacitações dos servidores, tendo em vista a mudança do quadro de funcionários desde 2006, e a necessidade da contínua discussão conceitual e procedimental relacionada à interdisciplinaridade;

b) a ampliação do quadro de analistas ambientais, responsáveis pela avaliação dos processos de licenciamento ambiental, em algumas SUPRAMs, considerando a demanda de licenças ambientais, tendo em vista que as exigências temporais dos empreendedores é diversa da exigência temporal de uma análise interdisciplinar;

c) a escolha como gestor de processos de servidores que tenham incorporado o espírito interdisciplinar, ou seja, que consigam integrar as várias contribuições dos diversos profissionais que compõem a equipe, bem como auxiliar o seu processo de diálogo.

\section{REFERÊNCIAS}

BRASIL. Lei n. 6.938/1981. Dispõe sobre a Política Nacional de Meio Ambiente, seus fins e mecanismos de formulação e aplicação. Brasília, 1981. Disponível em: <http://www.planalto.gov.br>. Acesso em: $24 / 08 / 2009$.

CONAMA. Resolução n. 237/1997. Disponível em: $<$ http://www.mma.gov.br>. Acesso em: 09/02/2006.

FAZENDA, I. C. A. Interdisciplinaridade: história, teoria e pesquisa. Campinas: Papirus, 2006.

O que é interdisciplinaridade? São Paulo:

Cortez, 2008.

FUNDAÇÃO ESTADUAL DE MEIO AMBIENTE. Manual informativo: treinamento institucional 2006 / Fundação Estadual do Meio Ambiente. Belo Horizonte: FEAM, 2006. 
FUNDAÇÃO JOÃO PINHEIRO. A Questão Ambiental em Minas Gerais: discurso e política. Belo Horizonte: FJP, 1996.

GONÇALVES, C. W. P. Os (des)caminhos do meio ambiente. São Paulo: Contexto, 1989.

GUIMARÃES, M. A dimensão ambiental na educação. Campinas: Papirus, 1995.

MORIN, E. A Religação dos Saberes. O desafio do século XXI. 3 ed. Rio de Janeiro: Bertrand Brasil, 2002.

LEFF, E. Saber Ambiental. Petrópolis: Vozes, 2002.

LENOIR, Y.; HASNI, A. La interdisciplinaridad: por um matrimonio abierto de la razón, de la mano e del corazón. Revista Ibero-Americana de Educación, Organización de Estados Iberoamericanos (OEI). n. 35, maio-agosto 2004.

LEIS, H. R. Um modelo político-comunicativo para superar o impasse do atual modelo político-técnico de negociação ambiental no Brasil. In: CAVALCANTI, C. (Org). Meio Ambiente, Desenvolvimento Sustentável e Políticas Públicas. SP: Cortez; Recife: Fundação Joaquim Nabuco, 2002.

MANGINI, F. N. da R.; MIOTO, R. C. T. A interdisciplinaridade na sua interface com o mundo do trabalho. Rev. Katálysis, Florianópolis, v. 12, n. 2, p. 207-215, dez. 2009. Disponível em: <http://www. scielo.br/scielo.php?script=sci_arttext\&pid=S141449802009000200010\&lng $=$ en $\& n r m=i s o>$. Acesso em: 17 fev. 2010.

MINAS GERAIS. Lei delegada n. 62, de 29 de janeiro de 2003. Disponível em: <http://www.siam. mg.gov.br>. Acesso em: 04 jan. 2010.

Lei n. 15.972, de 12 de janeiro de 2006. Disponível em: <http://www.siam.mg.gov.br>. Acesso em: 17 jan. 2008.

. Lei n. 7.772, de 08 de setembro de 1980. Disponível em: $<$ http://www.siam.mg.gov.br>. Acesso em: 04 jun. 2008.

Lei n. 17.600/2008, de 01 de julho de 2008. Disponível em: $<$ http://www.siam.mg.gov.br $>$. Acesso em: 05 jan.2009.

Decreto Estadual n. 44.667, de 03 de dezembro de 2007. Disponível em: <http://www.siam. mg.gov.br>. Acesso em: 05 jan. 2009.

Deliberação Normativa COPAM n. 74/2004, de 09 de setembro de 2004. Disponível em: <http:// www.siam.mg.gov.br>. Acesso em: 06 jun. 2010.

MORIN, E. A religação dos Saberes: o desafio do século XXI. Rio de Janeiro: Bertrand Brasil, 2002.

PAULA, C. de O. A Gestão de Pessoas nas Supram's - A Gestão de Pessoas nas Unidades Regionais do Sistema Estadual de Meio Ambiente (Sisema), após a Implantação do Programa Interdisciplinar. 2007. Monografia (Especialização em Gestão de Pessoas) - Escola de Governo de Minas Gerais (EGMG) da Fundação João Pinheiro - MG, 2007.

POMBO, O. Interdisciplinaridade e integração dos saberes. Liinc em Revista, v. 1, n. 1. Rio de Janeiro: UFRJ/IBICT, p. 3-15, mar. 2005

SÁNCHEZ, L. E. Avaliação de impacto ambiental: conceitos e métodos. SP: Oficina de Textos, 2008.

SECRETARIA DE ESTADO DE MEIO AMBIENTE E DESENVOLVIMENTO SUSTENTÁVEL DE MINAS GERAIS. Projeto Análise Interdisciplinar dos Processos de Regularização Ambiental. Apostila. s/ data.

SEMAD. Parecer Técnico GEDIN n. 158/2007 do Processo COPAM n. 15925/2006/001/2007.2008. Disponível em: $<$ http://www.meioambiente.mg.gov. br/copam/urcs/triangulo-mineiro $>$. Acesso em: 06 jun. 2010.

. Parecer Técnico GEDIN n. 208/2007 do Processo COPAM n. 10314/2006/001/2007. 2008. Dis- 
ponível em: <http://www.meioambiente.mg.gov.br/ copam/urcs/triangulo-mineiro $>$. Acesso em: 06 jun. 2010.

Parecer Técnico GEDIN n. 209/2007 do Processo COPAM n. 10203/2006/001/2007. 2008. Disponível em: <http://www.meioambiente.mg.gov.br/ copam/urcs/triangulo-mineiro $>$. Acesso em: 06 jun. 2010.

. Parecer Técnico GEDIN n. 253/2007 do Processo COPAM n. 2327/2007/001/2007. 2008. Disponível em: <http://www.meioambiente.mg.gov.br/ copam/urcs/triangulo-mineiro>. Acesso em: 06 jun. 2010 .

Parecer Técnico GEDIN n. 07/2008 do Processo COPAM n. 12616/2006/001/2007. 2008. Disponível em: <http://www.meioambiente.mg.gov.br/ copam/urcs/triangulo-mineiro $>$. Acesso em: 06 jun. 2010.

Parecer Técnico GEDIN n. 33/2008 do Processo COPAM n. 12914/006/001/2007. 2008. Disponível em: <http://www.meioambiente.mg.gov.br/ copam/urcs/triangulo-mineiro $>$. Acesso em: 06 jun. 2010 .

Parecer Único n. 183115/2008 do Processo COPAM n. 04978/2007/001/2007. 2008. Disponível em: <http://www.meioambiente.mg.gov.br/copam/ urcs/triangulo-mineiro $>$. Acesso em: 06 jun. 2010.

. Parecer Único n. 183115/2008 do Processo COPAM n. 03940/2006/004/2008. 2008. Disponível em: <http://www.meioambiente.mg.gov.br/copam/ urcs/triangulo-mineiro $>$. Acesso em: 06 jun. 2010.

. Parecer Técnico n. 242/2008 do Processo COPAM n. 04778/2006/001/2007. 2009. Disponível em: <http: www.meioambiente.mg.gov.br/copam/ urcs/triangulo-mineiro>. Acesso em: 06 jun. 2010. 